\title{
HERVIEU-LÉGER, Danièle. O peregrino e o convertido: a religião em movimento. Petrópolis: Vozes, 2008.
}

Rodrigo Coppe Caldeira*

Durante anos, os sociólogos da religião buscaram entender o processo que lançava progressivamente a religião para o ostracismo da esfera pública. Marca de um mundo, como alguns diriam, pré-moderno, a religião era vista como uma expressão da cultura humana que tendia ao desaparecimento. Hoje, em vista da permanência do fato religioso nas sociedades, os estudiosos deparam-se com novas perguntas e desafios intelectuais. Religião e modernidade não são mais vistas pelo signo da contradição e incompatibilidade, interpretação que situava o catolicismo como "religião por excelência" e que, indiscutivelmente, demonstrava esvaziamento principalmente na segunda metade do século XX. Frente aos novos movimentos religiosos dos anos 1960 e 1970, do engajamento político de crentes, como a teologia da libertação, a sociologia da religião passou a lançar novas perguntas e a reconsiderar as relações entre modernidade e religião. Passou-se, assim, a um olhar frente aos "processos de decomposição e de recomposição das crenças", visando à "singularidade das construções de crenças individuais, em seu caráter maleável, fluido e disperso" (p. 22).

Danièle Hervieu-Léger pode ser considerada hoje a figura que mais se destaca entre os sociólogos da religião que investigam as novas configurações religiosas da modernidade tardia. Atual presidente da École de Hautes Études en Sciences Sociales em Paris e responsável pela revista Archives des Sciences Sociales des Religions, Hervieu-Léger constrói sua reflexão em $O$ peregrino e o convertido, publicado originalmente em 1999, visando responder, mesmo que preliminarmente, a perguntas como esta: "como compreender ao mesmo tempo o processo histórico da secularização das sociedades modernas e o desdobramento de uma religiosidade individual, móvel e moldável que dá lugar a formas inéditas de sociabilidade religiosa?" (p. 30).

\footnotetext{
* Doutor em Ciências da Religião (UFJF), professor da PUC Minas. País de origem: Brasil. E-mail: rodrigocoppe@gmail.com
} 
Em seu primeiro capítulo - A religião despedaçada -, Hervieu-Léger trata da modernidade de forma mais ampla, visando compreender o que a caracteriza e como esse processo impactou a esfera religiosa. Para a socióloga, pode-se falar em uma "modernidade religiosa": a subjetivização e individualização da crença. As sociedades modernas vivem um verdadeiro paradoxo: ao mesmo tempo que se enfraquece o poder das instituições religiosas de enquadrar os fiéis, esfacelando visões de mundo e levando a insubordinação a qualquer instituição religiosa, abre-se espaço para que novas construções religiosas se sucedam. Surge uma liberdade jamais vista: os indivíduos constroem agora a sua fé, longe do resguardo de qualquer instituição. "A crença não desaparece, ela se desdobra, se diversifica", afirma a estudiosa. Os indivíduos afirmam uma "crença" ou espiritualidade a partir de uma bricolagem feita por eles mesmos. O que existe é uma desregulação das práticas e vivências.

No segundo capítulo - O fim das identidades religiosas herdadas -, Hervieu-Léger aborda a questão das identidades no mundo contemporâneo marcado pela modernidade religiosa. A partir de uma transformação das diversas dimensões das "referências coletivas", "rupturas de memória" e "reorganização de valores", a identidade passa a ser vista nas dinâmicas que levam ao processo de sua constituição. Como nos diz HervieuLéger, o indivíduo hoje experimenta o percurso de uma livre escolha no campo religioso, sem ter, por seu lado, uma necessidade de conformar-se com verdades de determinada instituição religiosa. O foco central do capítulo é a busca da estudiosa em compreender como se dá a transmissão de um patrimônio religioso e a formação de identidades religiosas na atualidade. Segundo a autora, as sociedades atuais são tão arreligiosas não por serem idealmente racionais, mas por se caracterizarem como sociedades amnésicas, sem referências a sentidos transmitidos de geração em geração a partir de uma memória coletiva. Em vista de uma liberdade jamais vista no campo religioso, os "bricoladores" não se filiam necessariamente a esta ou aquela tradição, mas recolhem elementos de uma e outra a seu bel-prazer, dando dinamicidade ao fenômeno da crença e fugindo das tentativas reguladoras das instituições. A identidade, assim, não é mais herdada, mas inserida em uma dinâmica na qual o sujeito é o principal agente da construção de crenças. A autora denomina essa dinâmica de trajetórias de identificação, demonstrando seu caráter de movimento e fluidez. Parece que é a mesma base conceitual que Boaventura Sousa Santos usa ao definir identidades como identificações em curso. Os processos de identificação 
religiosa passam então a uma articulação livre de quatro dimensões: comunitária, ética, cultural e emocional.

No terceiro capítulo - Figuras do religioso em movimento -, a socióloga, para exemplificar a dinâmica descrita acima, passa a tratar de uma figura conceitual que denomina de "peregrino". O peregrino é aquele que não se guia mais pelo badalar do sino e pela regularidade dos tempos e dos espaços religiosos. Ao contrário do praticante regular, o peregrino não constrói sua identidade manifestada cotidianamente a partir do vínculo entre crença e pertença. $\mathrm{O}$ peregrino é aquele que, respondendo às exigências da modernidade, que impõe ao indivíduo a produção de significados para a sua própria existência, constrói narrativamente sua experiência em confronto com uma linhagem religiosa que se identifica pessoalmente. Como exemplos nos quais é possível perceber o trânsito do peregrino, a autora cita as experiências de Taizé e as Jornadas Mundiais da Juventude.

No quarto capítulo - Figuras do religioso em movimento -, Hervieu-Léger trata da figura do "convertido". Para ela, o convertido é o melhor exemplo para a "identificação da formação das identidades religiosas nesse contexto de mobilidade". Segundo a autora, a desregulamentação da crença e o enfraquecimento da memória favorecem a circulação dos crentes, colocando-os frente aos seus próprios destinos. Além disso, essa desregulamentação favorece as conversões, que se dão a partir da individualidade subjacente às variadas disposições sociais e culturais. A figura do convertido torna-se um caráter exemplar para o conceito de modernidade religiosa já que a conversão se dá a partir de escolha individual, manifestando assim uma das grandes dimensões antropológicas da modernidade: a autonomia do indivíduo. Na página 116, a autora afirma: "O convertido manifesta e cumpre esse postulado fundamental da modernidade religiosa segundo o qual uma identidade religiosa 'autêntica' tem que ser uma identidade escolhida". Pode-se falar em três modelos principais de conversão: o primeiro deles é aquele do sujeito que "muda de religião" porque rejeita a tradição herdada; é uma condenação da experiência anterior e um abrir-se para uma nova. A socióloga fala em "protesto sociorreligioso". O segundo modelo é o das conversões dos "sem-religião". A partir de trajetória individual, o sujeito descobre certa tradição e integra-se a ela. Hervieu-Léger exemplifica, no caso francês, com as conversões dos jovens imigrados de até terceira geração que se convertem ao Islã. $\mathrm{O}$ terceiro e último modelo de convertido é aquele denominado de "reafiliado", "convertido de dentro". Esse é caracterizado por aqueles que vivem de maneira conformista a tradição 
recebida, até o momento em que redescobrem aquela identidade religiosa como possibilitadora do sentido.

No capítulo cinco - As comunidades sob o regime do individualismo religioso -, a autora se defronta com a questão da subjetivização e da individualização das crenças e práticas religiosas. Utilizando o conceito de "nebulosa místico-esotérica" de F. Champion, para falar sobre as mutações ocorridas no individualismo, Hervieu-Léger aponta uma das principais características da "modernidade religiosa": a insistência de uma "religiosidade inteiramente centrada no indivíduo e sua realização pessoal”. A questão não é aderir a uma verdade A ou B, mas experimentar, a partir de si mesmo, sua própria verdade, fora de enquadramentos e ortodoxias. Segundo a socióloga, essa "nebulosa" leva às últimas consequências as tendências expressas anteriormente. Elas desembocam, por um lado, na "valorização do mundo", a partir de uma noção de salvação que visa exclusivamente à vida terrestre, e por outro, na "afirmação da autonomia do sujeito crente". Dessa operação, surge a modernidade religiosa. Uma das questões abordadas por Hervieu-Léger nesse capítulo é a que gira em torno da origem dessa individualização da experiência religiosa. A estudiosa levanta a hipótese de que ela pode vir da própria espiritualidade católica do século XVII, marcada pela insistência em uma via "centrada na presença divina interior, pacificadora e satisfatória de Deus", que o próprio crente pode encontrar em busca da sua realização pessoal. Pergunta: "De maneira mais geral, pode-se perguntar se as efervescências espirituais rituais dos séculos XVII-XVIII não podem ser colocadas em relação, de modo mais ou menos direto, com a emergência inicial de um individualismo moderno que valoriza a realização psicológica do indivíduo”. Outra questão sobre a qual Hervieu-Léger também reflete são as possibilidades da vivência religiosa em comunidades, em um mundo marcado pelo individualismo religioso. Assim, o "crer sem pertencer" é uma das grandes marcas da conjuntura religiosa atual. O que ocorre é uma disjunção entre crença e pertença. Crer não pressupõe pertencer. Essa é uma das principais características da modernidade religiosa.

No último capítulo - Instituições em crise, laicidade em pane -, Hervieu-Léger aborda um dos temas mais em alta hoje em alguns campos das ciências humanas, principalmente na França: a questão da laicidade. A estudiosa oferece uma concisa história da religião na França, demonstrando como se deu o processo que levou à situação atual francesa, especialmente aquela que se desenvolve depois de 1789 e sua famosa Revolução. 
Insere também o Islã em sua análise, visando perceber como ocorre o processo de "assimilação" dos muçulmanos e como o Estado francês reagiu a eles até o momento. Além disso, também trata rapidamente da questão das "seitas". Para a socióloga, o importante não é saber se a crise dos mecanismos institucionais de validação da crença é "catástrofe para religião ou um benefício para os crentes", mas sim compreender suas implicações socioculturais.

Hervieu-Léger conclui a obra falando sobre uma "laicidade mediadora". Para ela, devido a alguns sinais que vêm da esfera pública, é possível notar alguns movimentos na relação entre estado laico e religiões. Segundo ela, "não se deixa de observar que as relações entre a república laica e as religiões podem se deslocar, e mesmo passar de um regime de neutralidade relativamente pacífica ao de uma cooperação razoável em matéria de produção das referências éticas, de preservação da memória e de construção do vínculo social”. De fato, tal questão foi abordada incisivamente pelo papa Bento XVI e pelo presidente francês Sarkozy por ocasião da visita do pontífice à França em 2008. HervieuLéger cita também o diálogo inter-religioso como uma das dinâmicas mais expressivas atualmente, que terá papel fundamental na organização de uma "laicidade mediadora". Se as instituições passam por profunda desregulação, perdendo a capacidade de enquadrar a crença, resta ao Estado intermediar o debate a fim de que se defenda a liberdade religiosa dos estados democráticos.

Com esta obra agora editada no Brasil, o leitor terá um quadro geral da questão religiosa nos tempos atuais e perceberá que a religiosidade, a religião, a crença e a prática, realizadas fora dos âmbitos institucionais, transformam a paisagem sociocultural contemporânea. 